\title{
Age-Related Differences in the Direct Cardiac Effects of Cisapride: Narrower Safety Range in the Hearts of Young Rabbits
}

\author{
MEI-HWAN WU, MING-JAI SU, AND SELMA SIU-MAN SUN \\ Departments of Pediatrics [M.-H.W., S.S.-M.S.] and Pharmacology [M.-J.S.], College of Medicine, \\ National Taiwan University, National Taiwan University Hospital, Taipei, Taiwan
}

\begin{abstract}
ABST
Although cisapride is widely used to treat gastrointestinal
motility disorders, it has been associated with QT prolongation,
torsades de pointes, and cardiac arrest. Only in children, how-
ever, has atrioventricular (AV) block after cisapride been re-
ported. This study used Langendorff perfusion to determine the
direct effects of cisapride $(0.03,0.1,0.3$, and $1 \mu \mathrm{M})$ on the
conduction properties of neonatal $(<7$ d) and adult $(>3$ mo)
rabbit hearts. At a clinically relevant dose $(0.03 \mu \mathrm{M})$, cisapride
slowed the recovery of the His-Purkinje system. At $0.1 \mu \mathrm{M}$, the
refractoriness of the His-Purkinje system and conduction through
this system were prolonged. Corrected QT intervals and the
ventricular refractory period were also lengthened. These param-
eters were significantly more prolonged in neonates than in
adults. The level of AV block at rapid atrial pacing shifted from
the AV node to the His-Purkinje system, with an ED ${ }_{50}$ of 0.06
\end{abstract}
Cisapride, a widely used gastrointestinal prokinetic agent, has been associated with the development of prolonged QT interval, malignant ventricular arrhythmias, and sudden death $(1,2)$. Cisapride is a gastrointestinal prokinetic agent that facilitates gastrointestinal motility by increasing lower esophageal sphincter pressure and improving gastric emptying (3). The mechanism of such gastrointestinal action is attributable to an enhanced release of acetylcholine at the mesenteric plexus as well as a direct suppression of human ether-a-go-go-related gene (HERG)-like $\mathrm{K}^{+}$currents in the esophageal smooth muscle $(4,5)$. As for the mechanisms underlying the adverse cardiac effects, a direct inhibition of the repolarizing $\mathrm{K}^{+}$ current and the subsequent prolongation of action potential have previously been suggested. In rabbit Purkinje fibers, cisapride $(0.1-10 \mu \mathrm{M})$ lengthened the action potential duration in a concentration-dependent and reverse rate-dependent man-

Received August 3, 2001; accepted November 4, 2002.

Correspondence: Mei-Hwan Wu, M.D., Department of Pediatrics, National Taiwan University Hospital, No. 7 Chung-Shen South Road, Taipei, Taiwan, 100; e-mail: mhwu@ha.mc.ntu.edu.tw

This study was supported by the National Science Council, R.O.C., and in part by the Cardiac Children Foundation, R.O.C. (CCF99-04).

DOI: 10.1203/01.PDR.0000050122.67091.1D and $0.52 \mu \mathrm{M}$ in the neonate and the adult, respectively. In the neonate, cisapride even resulted in infranodal AV block rhythm $($ ED50 $=0.12 \mu \mathrm{M})$, but this was not the case in the adult. Polymorphic ventricular tachycardia after cisapride was induced in one in seven neonates $(14 \% ; 0.1 \mu \mathrm{M})$ and in one in seven adults $(14 \% ; 0.03 \mu \mathrm{M})$. It is concluded that cisapride may affect the refractoriness of cardiac tissue and that the His-Purkinje system seems to be the most sensitive. In neonatal hearts, this modification may, in fact, progress to infranodal AV block. Such susceptibility to cisapride strongly indicates that the therapeutic safety range used for the young heart should be narrowed. (Pediatr Res 53: 493-499, 2003)

ner, and early after-depolarizations with the succeeding triggered activity were observed at abruptly decelerating pacing rates (6). Apart from this, in isolated rabbit myocytes, the rapid component of the delayed rectifying $\mathrm{K}^{+}$current $\left(\mathrm{I}_{\mathrm{Kr}}\right)$ was blocked by cisapride with an $\mathrm{IC}_{50}$ of $9 \mathrm{nM}(7)$.

In the immature heart, the presence of age-related differences in the $\mathrm{K}^{+}$repolarizing currents has been well documented $(8,9)$, but whether these differences make immature hearts more vulnerable to cisapride has yet to be determined. According to a report of the US Food and Drug Administration Medwatch program, seven of 57 arrhythmias associated with cisapride treatment occurred in children (2). In a cohort of 35 children, $31 \%$ of the patients developed a prolongation of the QT interval beyond the normal range ( $\geq 450 \mathrm{~ms}$ ) after cisapride treatment (10). In adults, adverse cardiac effects were attributed to prolonged QT intervals, leading to a malignant form of ventricular tachycardia. Only in children has the development of 2:1 atrioventricular (AV) block been reported (11). We therefore conducted this study to identify changes in cardiac electrophysiology after the administration of cisapride in isolated Langendorff-perfused hearts. This experimental design allowed for the determination of the direct cisapride effects on 
cardiac conduction as well as for any age-related differences in these effects.

\section{METHODS}

The institutional research committee approved the experimental design of this study. Anesthesia (sodium pentobarbital, $30 \mathrm{mg} / \mathrm{kg}$ ) and heparin (300 units $/ \mathrm{kg}$ ) were administered i.p. to neonatal $(<7$ d) and i.v. to adult $(>3$ mo) New Zealand White rabbits.

\section{Intracardiac ECG Recording}

Animal preparation. Our methods have been described elsewhere (12), but in brief, the heart was excised via thoracotomy, and the aorta was retrogradely perfused. For pacing the atria, a high right atrial electrode was placed near the junction of the superior vena cava and the right atrium. A bipolar electrode consisting of a tungsten-soldered silver wire was placed on an area near the apex of the triangle of Koch to record the His bundle electrograms. In the next stage, ventricular recording electrodes were placed on the epicardium of the right ventricular apex, thereby providing easily recognizable $\mathrm{T}$ waves, and a ventricular pacing electrode was placed on the pericardium near the right ventricular apex. In the pacing studies, a programmable stimulator (Bloom Ltd, DTU 215) was used, with the pacing stimulus set at three times the diastolic threshold voltage for $1 \mathrm{~ms}$ in duration. The signal was continuously monitored on an oscilloscope (Hewlett Packard, 54503A), and pertinent data were recorded on a two-channel physiologic recorder (Gould, RS 3200) with a paper speed of $100 \mathrm{~mm} \mathrm{~s}^{-1}$.

Experimental protocol. An average of four stable cycle lengths of spontaneous heartbeats were taken as the basic cycle length. The QT interval and corrected QT interval (corrected by the square root of the RR interval) were used as the parameters for monitoring ventricular repolarization. The right atrium was then paced at a constant rate, which was slightly faster than the spontaneous heart rate. At this constant pacing rate, the intra-atrial conduction time (SA interval), AV nodal conduction time (AH interval), and the His-Purkinje conduction time (HV interval) were measured.

Incremental right atrial pacing rates were used to determine the Wenckebach cycle length - that is, the point at which the 1:1 AV conduction was lost. Atrial extrastimulation $\left(\mathrm{S}_{1} \mathrm{~S}_{2}\right)$ was also performed to obtain the refractory periods of the atrial, $\mathrm{AV}$ node and the His-Purkinje system. The basic driving pacing cycle length $\left(\mathrm{S}_{1} \mathrm{~S}_{1}\right)$ was maintained at $250 \mathrm{~ms}$ for the neonates and $400 \mathrm{~ms}$ for the adults throughout the experiment. The ventricular effective refractory period was similarly determined by a ventricular extrastimulation study protocol.

Control values for each measurement were taken after perfusion with Tyrode's solution for at least $30 \mathrm{~min}$. Experimental values for each concentration of cisapride $(0.03,0.1,0.3$, and $1 \mu \mathrm{M})$ were determined after perfusion with cisapridecontaining Tyrode's solution for $10 \mathrm{~min}$. Each concentration of cisapride was given in a sequential cumulative pattern. Finally, wash data were obtained after washing with Tyrode's solution for $1 \mathrm{~h}$.
Solutions. Tyrode's solution contained (in $\mathrm{mM}$ ) $120.3 \mathrm{NaCl}$, $1.2 \mathrm{NaH}_{2} \mathrm{PO}_{4}, 24.2 \mathrm{NaHCO}_{3}, 5 \mathrm{KCl}, 1.3 \mathrm{MgCl}_{2}, 1.2 \mathrm{CaCl}_{2}$, and 11 glucose; this was saturated with $95 \% \mathrm{O}_{2}$ and $5 \% \mathrm{CO}_{2}$ to yield a pH of 7.4, and subsequently the solution was warmed to $37^{\circ} \mathrm{C}$.

\section{Statistics}

The data were expressed as the mean \pm 1 SEM for each parameter, and the data in the form of ratios (where appropriate) were used for statistical comparisons. A two-way repeated-measures ANOVA was used to examine the significance of the differences between the two age groups for each parameter (13). The significance of the changes for each concentration of cisapride compared with that of the control values was determined by a Student's paired $t$ test. Because the drug testing was cumulative in nature, the significance of the differences between two concentrations was not reported, and only differences of $p<0.05$ were considered to be statistically significant.

\section{RESULTS}

Changes with regard to the electrophysiological parameters after cisapride treatment were assessed in seven neonatal and seven adult rabbit hearts. Intracardiac recordings detected the atrial activities, the His potential, and ventricular activities and repolarization ( $\mathrm{T}$ waves). Representative electrograms before and after cisapride application are shown in Fig. 1 (adult rabbits; control, $0.03,0.1,0.3$, and $1 \mu \mathrm{M}$ cisapride and wash) and Fig. 2 (neonatal rabbits; 0.03, 0.1, and $0.3 \mu \mathrm{M}$ cisapride and wash). Because the neonatal rabbit heart developed AV block after $0.3 \mu \mathrm{M}$ cisapride, the effects of cisapride at $1 \mu \mathrm{M}$ were not examined in the neonatal rabbits. The changes in the electrophysiological parameters after cisapride treatment are summarized in Table 1. We found that the electrophysiological parameters in adult rabbit hearts exposed to cisapride could not be completely restored to baseline levels after washing with Tyrode's solution for $1 \mathrm{~h}$. The same situation existed but to a

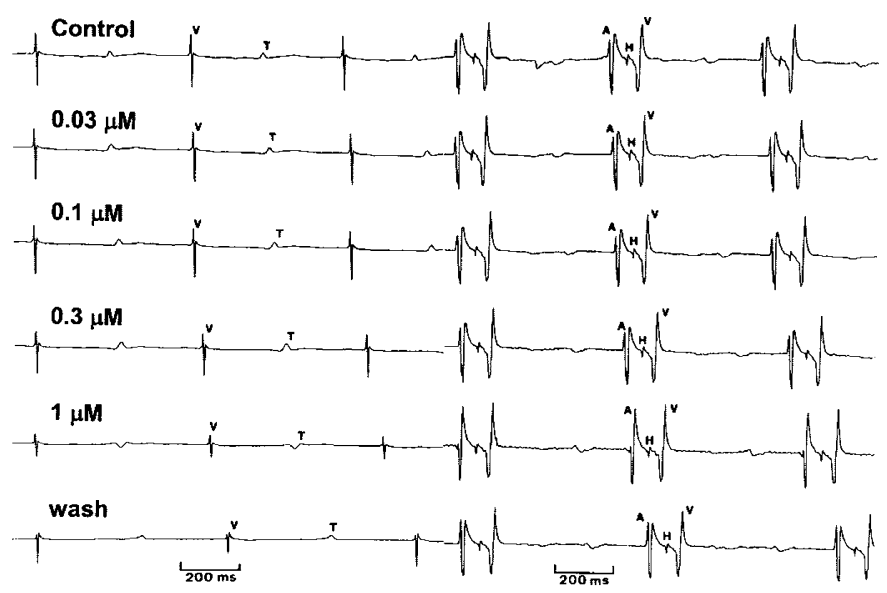

Figure 1. Representative His bundle electrograms (right) and ventricular electrograms (left) of an adult rabbit heart before and after cisapride $(0.03,0.1$, 0.3 , and $1 \mu \mathrm{M}$ cisapride) as well as after washout of the cisapride. Cisapride prolonged the corrected QT intervals in a dose-dependent manner. A, atrial activity; $\mathrm{H}$, His potential; $\mathrm{T}$, $\mathrm{T}$ wave; $\mathrm{V}$, ventricular activity. 


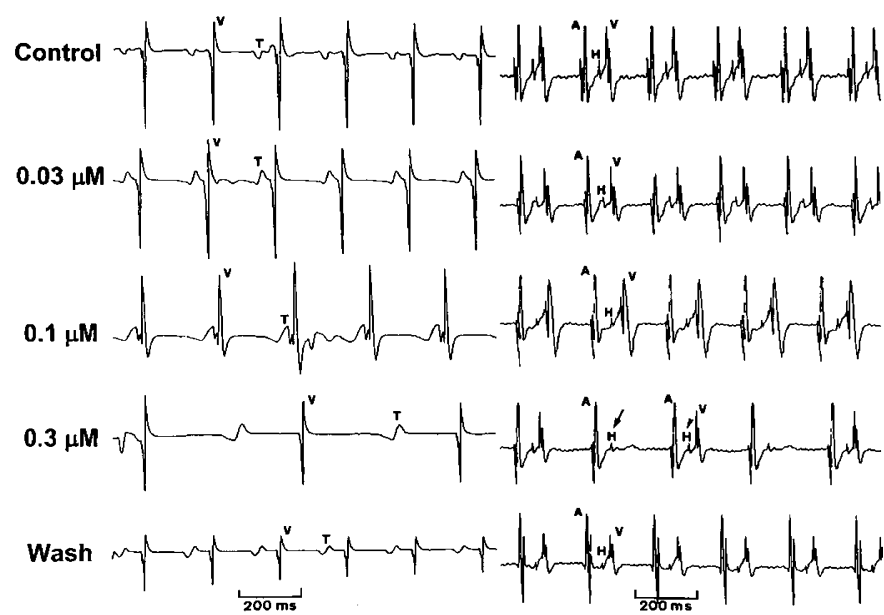

Figure 2. Representative His bundle electrograms (right) and ventricular electrograms (left) of a neonatal heart before and after cisapride $(0.03,0.1$, and $0.3 \mu \mathrm{M}$ cisapride) as well as after washout of the cisapride. The neonatal rabbit heart developed the AV block after $0.3 \mu \mathrm{M}$ cisapride; therefore, the effects of cisapride at $1 \mu \mathrm{M}$ were not examined. Cisapride also prolonged the corrected QT intervals in a dose-dependent manner, and the prolongation was more evident in the neonate than in the adult. At $0.3 \mu \mathrm{M}$ cisapride, the rabbit heart developed 2:1 infranodal AV block. The arrowhead indicated a ventricular activation after the His potential (conducted beat), but the arrow indicated no ventricular activation after the His potential (nonconducted beat at the infranodal level). This atrioventricular block was restored after washout of the cisapride. A, atrial activity; $\mathrm{H}$, His potential; $\mathrm{T}$, $\mathrm{T}$ wave; $\mathrm{V}$, ventricular activity.

lesser extent in the neonatal rabbits. Therefore, the time control of the present experiment model was examined in another two adult rabbits to determine the effects (if any) of perfusing with Tyrode's solution over time. Using the present experimental setting, no parameter changed significantly for $3 \mathrm{~h}$ (data not shown). In addition, the changes in the electrophysiological parameters with time after washout of cisapride $(1 \mu \mathrm{M})$ were assessed in two other adult rabbits. The changes persisted even after washing with normal Tyrode's solution for $2 \mathrm{~h}$. On the basis of these controls, the changes after cisapride in adult rabbits were deemed as partially irreversible effects caused by cisapride. No previous studies have documented the reversibility of changes as a result of cisapride in mature animals $(4,6$, $7,14)$.

Rhythm disturbances. Cisapride $(0.1 \mu \mathrm{M})$ resulted in infranodal AV block (2:1 blocked below the His potential) in three of the seven neonatal rabbits (Fig. 2). At $0.3 \mu \mathrm{M}$, all of the neonatal hearts developed AV block, with the AV block varying from $4: 3$ to $2: 1$, all but one being ratios below the His potential. In the presence of AV block, the AH interval remained minimally prolonged, but the $\mathrm{HV}$ interval progressively lengthened and led to the AV conduction block. The AV block could be converted by washing out the cisapride in all neonatal rabbit hearts along with a recovery of the QT interval prolongation. The $\mathrm{ED}_{50}$ for the development of infranodal $\mathrm{AV}$ block rhythm by cisapride in the neonate rabbit hearts was 0.12 $\mu \mathrm{M}$. In contrast, none of the adult rabbit hearts developed the AV block. The elevation of extracellular (perfusate) $\mathrm{K}^{+}$level to $6 \mathrm{mM}$ failed to prevent the development of the AV block in the neonatal rabbit hearts after cisapride. Polymorphous ven- tricular tachycardia was induced by programmed ventricular extrastimulation in one neonatal rabbit $(1 / 7 ; 14 \%)$ with cisapride $0.1 \mu \mathrm{M}$ and in one adult $(1 / 7 ; 14 \%)$ with cisapride 0.03 $\mu \mathrm{M}$ (Fig. 3).

Spontaneous cycle length. Neither spontaneous sinus nor atrial cycle length, in the absence of the development of AV block, was significantly changed by cisapride.

QT interval and ventricular electrophysiological functions. Cisapride at the clinically relevant dose $(0.1 \mu \mathrm{M})$ prolonged the QT intervals in both the neonates and the adults. Higher concentrations of cisapride might have induced infranodal block. Because the corrected QT interval would not be a good index of ventricular repolarization in the presence of AV block, only the QT intervals measured during 1:1 conduction were analyzed. QT prolongation was significantly greater in the neonates than in the adults.

The QT intervals measured during the stage with incremental atrial pacing rates determined the degree of QT intervals shortening at faster heart rates. At high pacing rates, when the phenomenon of $\mathrm{T}$ wave alternans developed or the $\mathrm{Q}$ wave was fused with the next ventricular activation wave, the QT intervals were not measured. We found that the QT interval could progressively be shortened as the pacing atrial cycle length was shortened. This relationship persisted for neonates and adults given with cisapride (Fig. 4). Because the QT interval may have changed with cycle length, the cisapride-induced changes in the QT intervals were compared at the same atrial pacing cycle length of $300 \mathrm{~ms}$ (Fig. 5). We found under these conditions that the QT interval was still significantly more prolonged in the neonates.

The ventricular refractory period was significantly increased at the clinically relevant concentration $(0.1 \mu \mathrm{M})$ in the neonates and adults, alike. However, the extent of the lengthening of the ventricular refractory period was significantly higher in the neonates.

His-Purkinje function. The effective refractory period of the His-Purkinje system increased at clinically relevant concentra-
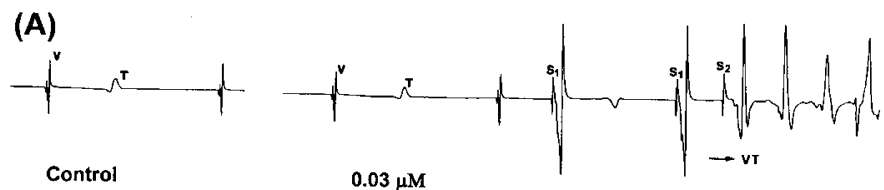

Control
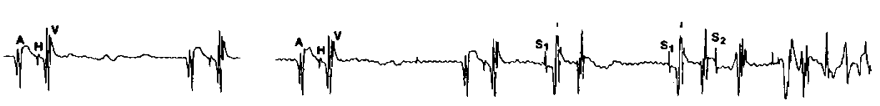

(B)

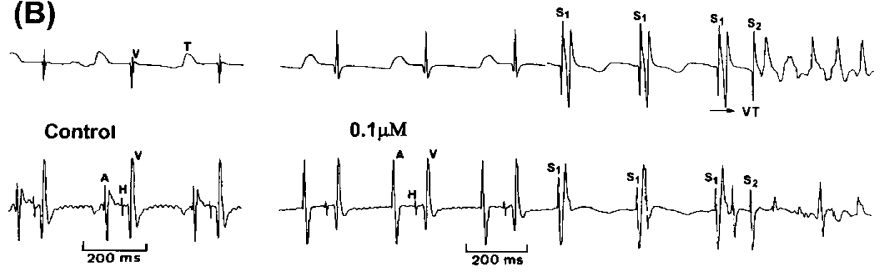

Figure 3. (A) After $0.03 \mu \mathrm{M}$ of cisapride, by ventricular extrastimulation $\left(\mathrm{S}_{1} \mathrm{~S}_{2}\right)$, ventricular tachyarrhythmia $(V T)$ was induced in an adult rabbit heart. (B) After $0.1 \mu \mathrm{M}$ of cisapride, ventricular extrastimulation $\left(\mathrm{S}_{1} \mathrm{~S}_{2}\right)$ also induced VT in a neonatal rabbit heart. A, atrial activity; $\mathrm{H}$, His potential; T, T wave; $\mathrm{V}$, ventricular activity. 
Table 1. Changes in the electrophysiological parameters after cisapride $(\mu M)$ in the neonatal and adult rabbit hearts

\begin{tabular}{|c|c|c|c|c|c|c|c|c|c|c|c|c|c|}
\hline & \multicolumn{6}{|c|}{ Adult $(n=7)$} & \multicolumn{6}{|c|}{ Neonate $(n=7)$} & \multirow[b]{2}{*}{$p$} \\
\hline & $(-)$ & 0.03 & 0.1 & 0.3 & 1 & Wash & $(-)$ & 0.03 & 0.1 & 0.3 & 1 & Wash & \\
\hline $\mathrm{BCL}$ & $475(16)$ & $480(16)$ & 507 & $518(25)$ & $508(26)$ & $554(27)$ & $296(22)$ & $278(22)$ & 305 & 316 & -- & 293 & \\
\hline \multirow[t]{2}{*}{$\mathrm{QT}_{\mathrm{c}}$} & $368(9)$ & $383(9)$ & $402 *(9)$ & $430 *(5)$ & $450 *(5)$ & $469 *(8)$ & $405(13)$ & 427 (12) & $480 *(13)$ & $559 *(42)$ & -- & 440 (14) & \\
\hline & $100(0)$ & 104 (1) & $109(2)$ & $117(2)$ & $122(2)$ & $122(2)$ & $100(0)$ & $106(3)$ & $119(3)$ & $149(20)$ & -- & $109(5)$ & $0.01 *$ \\
\hline WCL & $237(12)$ & $248(21)$ & $250(19)$ & $263(14)$ & $292 *(8)$ & $297 *(15)$ & $166(8)$ & $176(8)$ & $213 *(8)$ & $365 *(75)$ & -- & $184(9)$ & \\
\hline SA & 100 & $102(2)$ & $110(8)$ & $114(11)$ & 104 & 100 & 100 & $100(0)$ & $102(3)$ & $103(3)$ & -- & $103(2)$ & 0.46 \\
\hline \multirow[t]{2}{*}{$\mathrm{AH}$} & & $60(8)$ & $59(5)$ & $61(8)$ & $63(5)$ & $59(3)$ & $53(3)$ & $55(3)$ & $62(7)$ & $60(0)$ & -- & $60(5)$ & \\
\hline & $100(0)$ & $103(4)$ & $103(2)$ & $106(6)$ & $111(5)$ & $100(6)$ & $100(0)$ & $104(3)$ & $104(2)$ & $120(0)$ & -- & $115(16)$ & 0.48 \\
\hline \multirow[t]{2}{*}{ HV } & $30(2)$ & $30(2)$ & $31(2)$ & $32(2)$ & $35(2)$ & $33(3)$ & $18(2)$ & $18(2)$ & $23(2)$ & $23(8)$ & -- & $20(2)$ & \\
\hline & $100(0)$ & $100(0)$ & $102(2)$ & $106(3)$ & $115(5)$ & $108(3)$ & $100(0)$ & $100(0)$ & $130(6)$ & $145(5)$ & -- & $115(5)$ & $0.01 *$ \\
\hline AERP & $87(6)$ & $85(8)$ & $87(6)$ & $87(9)$ & $95(10)$ & $95(10)$ & $77(8)$ & $78(7)$ & $90(10)$ & -- & -- & $86(10)$ & \\
\hline \multirow[t]{2}{*}{ VERP } & $197(6)$ & 197 (13) & $218 *(5)$ & $233 *(7)$ & $243 *(8)$ & $235^{*}(12)$ & 167 (12) & $171(15)$ & $195 *(14)$ & $213 *(31)$ & $305 *(5)$ & 177 (15) & \\
\hline & $100(0)$ & $99(4)$ & $111(3)$ & 119 (4) & $124(6)$ & $120(6)$ & $100(0)$ & $103(8)$ & $120(10)$ & $167(4)$ & $185(10)$ & $113(8)$ & $0.01 *$ \\
\hline
\end{tabular}

BCL, basic cycle length; QTc, corrected QT interval; WCL, Wenckebach cycle length; SA, sinoatrial conduction interval; AH, atrio-His bundle conduction interval; HV, His-ventricular conduction interval; AERP, atrial effective refractory period; AVERP, AV nodal effective refractory period; HPERP, His-Purkinje system effective refractory period; VERP, ventricular effective refractory period.

$* P<0.05$.

tions dose dependently in the neonates and the adults. Although the period was more prolonged with the neonates, no statistical significance was evident. This may be explained, at least partially, by the missing data rejected after the development of the infranodal AV block in the neonates at the concentration of $0.3 \mu \mathrm{M}$. The conduction through the His-Purkinje system was prolonged by cisapride but significantly more prolonged in the neonates. The recovery curves of the HisPurkinje system $\left(\mathrm{H}_{2} \mathrm{~V}_{2}\right.$ versus $\mathrm{V}_{1} \mathrm{H}_{2}$ relation) were shifted to the right dose dependently in the neonates and the adults (Fig. 6). In the neonates, AV conduction was blocked at the HisPurkinje system (below the His potential) with higher concentrations of cisapride.

$A \boldsymbol{V}$ nodal function. Although the conduction through the AV node was not significantly modified by cisapride, the refractory period could be prolonged in the neonate and the adult with higher concentrations of cisapride. The AV nodal recovery curves (i.e. the $\mathrm{A}_{2} \mathrm{H}_{2}$ versus $\mathrm{H}_{1} \mathrm{~A}_{2}$ relations) were also shifted to the right after cisapride in both the adult and neonate but to a much smaller degree than the shift of the His-Purkinje recovery curves. The Wenckebach AV block during incremental rapid atrial pacing initially occurred above the level of the AV node (above the His bundle activation) in all control neonatal and adult rabbit hearts. It did, however, shift to the level of the His-Purkinje system (below the His bundle activation, infranodally) after cisapride with an $\mathrm{ED}_{50}$ of 0.06 and $0.52 \mu \mathrm{M}$ in the neonate and adult rabbits, respectively.

Atrial electrophysiological function. Cisapride did not significantly alter conduction through the atrial tissue (SA interval) or the refractoriness of the atrial tissue (atrial effective refractory period) in either the neonates or the adults.

\section{DISCUSSION}

Cisapride is a widely used prokinetic agent that is clinically useful for the improvement of gastrointestinal motility disorders (3). The major adverse cardiac effects in infants and adults are related to a prolonged QT interval and subsequent ventricular arrhythmias and torsades de pointes $(1,2)$. In infants, the prolonged QT interval had previously been associated with a 2:1 AV block (11). The data presented here are the first to present in detail the electrophysiological changes that occur after cisapride in intact isolated neonatal and adult rabbit hearts. Besides noting the prolongation of the QT interval, we also identified a high susceptibility of the His-Purkinje system to cisapride. The QT interval and the refractoriness of the His-Purkinje system were prolonged by cisapride in both neonatal and adult hearts. However, the degree of prolongation was significantly greater in the neonates. Such modification may have even progressed to the infranodal AV block rhythm in the neonates. Our observations are indicative of the electrophysiological mechanisms involved in the adverse cardiac effects resulting from cisapride.

Electrophysiological modifications by cisapride at low concentrations. Whereas in adults the effective plasma levels of cisapride varied from 0.15 to $0.30 \mu \mathrm{M}$ (15), in the young infants receiving enterally administered cisapride for gastroesophageal reflux, the plasma concentration determined from 108 samples showed a greater variation ranging from 0.03 to $0.35 \mu \mathrm{M}(16)$. In the presence of ketoconazole or other agents that inhibit the cytochrome P450 3A4 enzyme system, the levels of cisapride can even be sharply higher. Even when the extensive plasma protein binding of cisapride is considered 
(A)

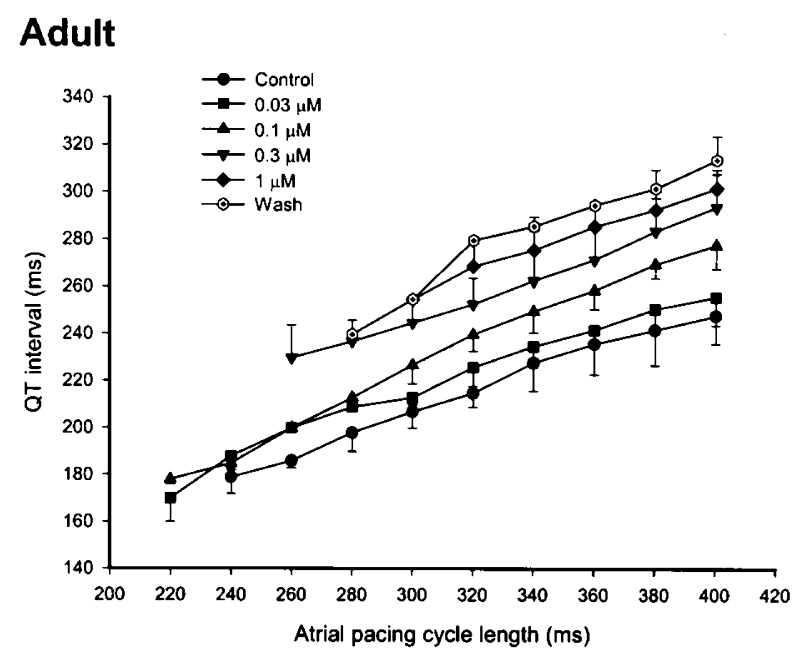

(B)

\section{Newborn}

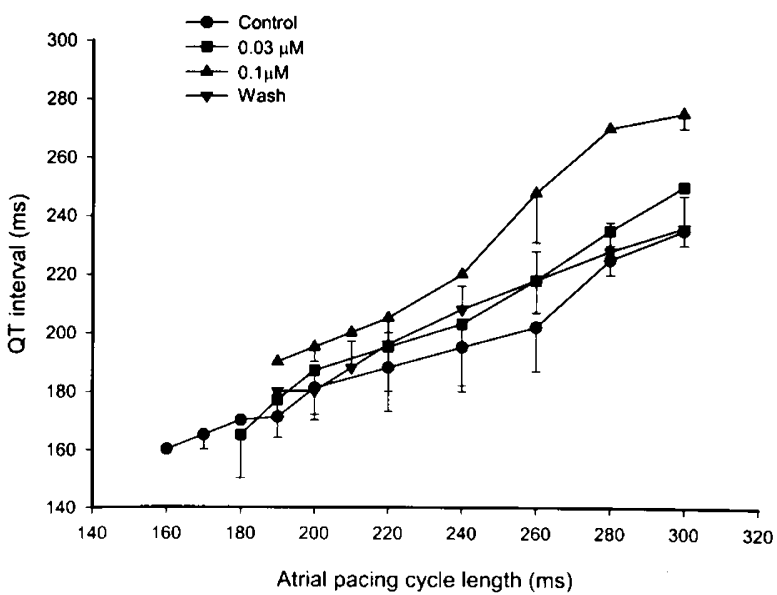

Figure 4. Relationship between the atrial pacing cycle lengths and the QT intervals after cisapride in adult $(A)$ and neonatal rabbits $(B)$. The QT interval was progressively shortened as the pacing atrial cycle length shortened. This relationship persisted for neonates and adults given cisapride.

(95-98\%), concentrations of free drug can still reach the low concentration range used in this experiment $(15,16)$. At the lowest concentration $(0.03 \mu \mathrm{M})$ used in the present study, none of the electrophysiological parameters was significantly altered. However, a right shift in the recovery curves of the His-Purkinje system was observed in both the neonates and the adults. Among the cardiac tissues, the action potential duration of the His-Purkinje system was the longest. An earlier study in isolated Purkinje fibers showed a stronger effect of cisapride in fibers with action potential duration longer than $300 \mathrm{~ms}$ (6). In isolated rabbit cardiac tissues, the action potential (at $90 \%$ repolarization) was increased by $22 \pm 1.5 \%$ and $48 \pm 5.6 \%$ in the ventricular muscle and the Purkinje fibers, respectively (7). Therefore, the His-Purkinje system, being the cardiac tissue with the longest duration of action potential can justifiably be considered the most vulnerable of all cardiac tissues to cisapride and, therefore, may be modified with clinically relevant doses of cisapride, as our experiments have shown.
(A)

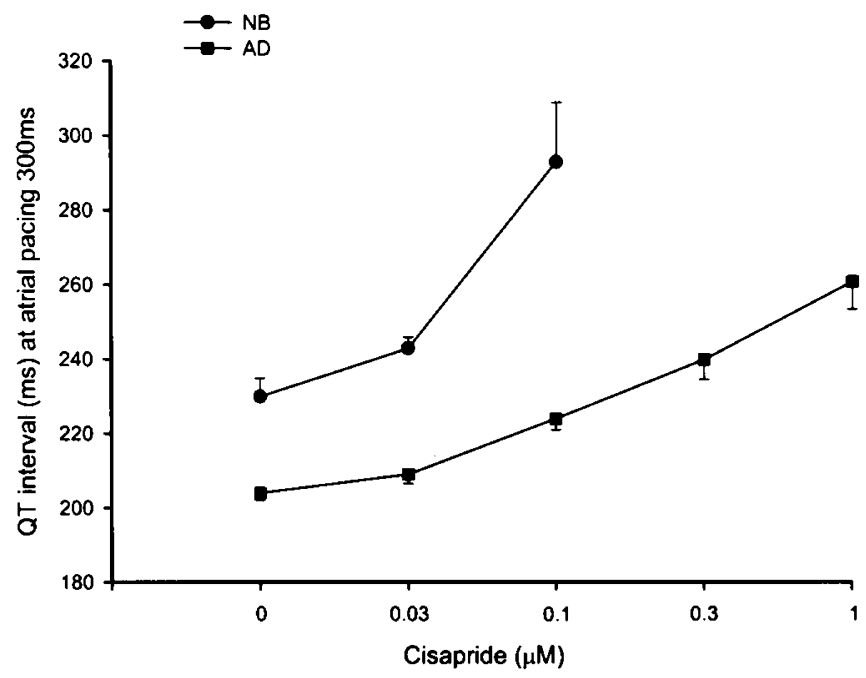

(B)

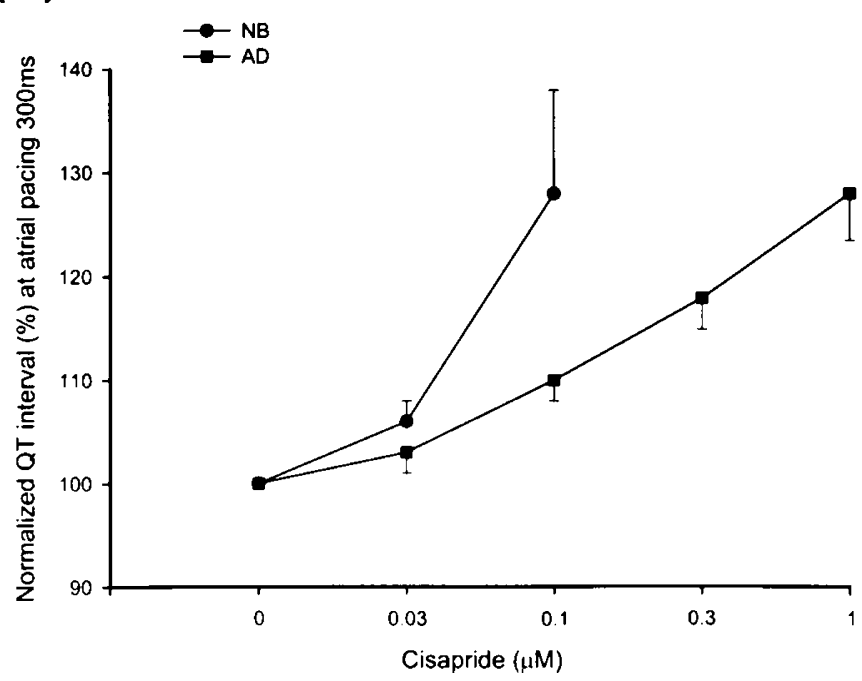

Figure 5. Cisapride-induced changes in the QT intervals were compared at the same atrial pacing cycle length of $300 \mathrm{~ms}$ in neonatal and adult rabbits. The QT interval $(A)$ and the normalized QT interval $(B)$ were significantly more prolonged in the neonate than in the adult.

Potential cisapride effects on cardiac conduction and agerelated differences. At the concentrations $0.1-1 \mu \mathrm{M}$, we found that the conduction and refractory periods of the His-Purkinje system and the refractoriness of the AV and ventricular tissues were prolonged. With corrected QT intervals lengthened, changes were in a dose-dependent manner and were significantly greater in the neonates. In both neonates and adults, the AV block during rapid atrial pacing shifted from the nodal to the infranodal level after cisapride. These data clearly indicate that the His-Purkinje system had a higher sensitivity to cisapride than did the AV nodal tissue. Besides this, the $\mathrm{ED}_{50}$ for such a shift was much lower in the neonates in whom infranodal AV block rhythm might well have further occurred with an $\mathrm{ED}_{50}$ of $0.12 \mu \mathrm{M}$. In contrast, the AV block rhythm was not observed in adult rabbit hearts. Such findings echo the clinical observations of cisapride toxicity, i.e. the findings of ventricular arrhythmias in both children and adults and of AV block 
(A)

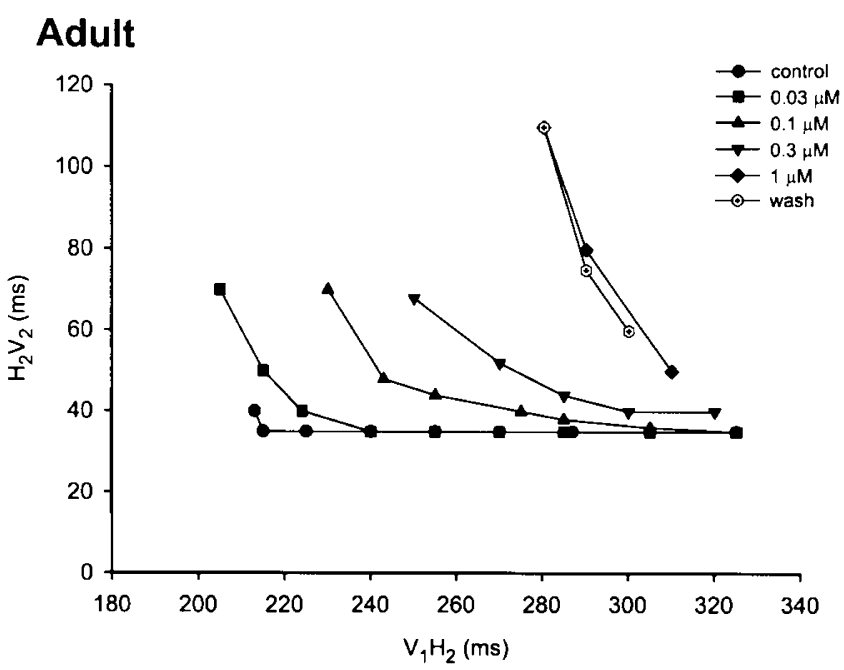

(B)

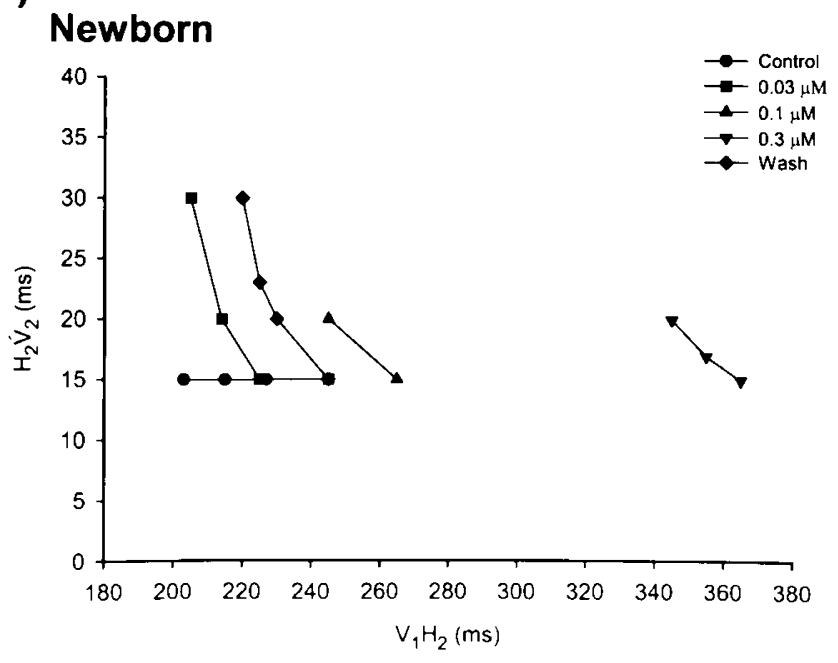

Figure 6. Recovery curves of the His-Purkinje system in a neonatal and an adult rabbit heart before and after cisapride. Cisapride caused a right shift of the recovery curves of the His-Purkinje system $\left(\mathrm{H}_{2} \mathrm{~V}_{2}\right.$ vs $\mathrm{V}_{1} \mathrm{H}_{2}$ relation) dose dependently in both the neonate and the adult. Only in the neonate was AV conduction blocked at the His-Purkinje system (below the His potential) as a result of higher concentrations of cisapride.

only in children $(1,2,11)$. On the basis of the present data, we suggest that cisapride may markedly prolong the refractoriness and conduction of the His-Purkinje system, which may, in turn, give way to further AV block in the Purkinje system in young hearts.

Cisapride-induced arrhythmias have been attributed to an inhibition of the $\mathrm{I}_{\mathrm{Kr}}$ and a subsequent prolonged duration of the action potential, an action much like the class III antiarrhythmic effect in Vaughan-Williams' classification $(6,7)$. The potency of cisapride $\left(\mathrm{IC}_{50}=44.5 \mathrm{nM}\right)$ for the HERG channel was in line with that of the class III antiarrhythmic agent dofetilide $\left(\mathrm{IC}_{50}=15.5 \mathrm{nM}\right)$ (14). Not unlike the case with rabbits, in which cisapride could suppress the $\mathrm{I}_{\mathrm{Kr}}$ with an $\mathrm{IC}_{50}$ of $9 \mathrm{nM}$ (7), in guinea pigs, animals with repolarizing currents that contain the $\mathrm{I}_{\mathrm{Kr}}$ and $\mathrm{I}_{\mathrm{Ks}}$, cisapride similarly suppressed the $\mathrm{I}_{\mathrm{Kr}}$ to a greater extent than it did the $\mathrm{I}_{\mathrm{Ks}}(17)$. Although we have identified the significantly more increased refractoriness of the His-Purkinje system, AV tissue and ventricular tissue after cisapride in the neonate compared with the adult, the underlying ionic mechanisms remain undefined. Cisapride blockage of the $\mathrm{I}_{\mathrm{Kr}}$ is associated with a high affinity to open and/or inactivated states (18). The $\mathrm{I}_{\mathrm{Kr}}$ is the major voltage-dependent and time-dependent repolarizing current of rabbit ventricular and Purkinje myocytes $(19,20)$. Selective $\mathrm{I}_{\mathrm{Kr}}$ blockers increase action potential duration to a greater extent at longer cycle lengths, a property that is known as "reverse use dependence" (21). In general, the neonatal Purkinje fibers have shorter action potential duration and a less negative resting membrane potential than their adult counterparts (22). At the same atrial pacing cycle length, we also noted that the QT intervals were still more prolonged in the neonate than in the adult. Therefore, a higher sensitivity to cisapride in the neonatal hearts obviously cannot be explained by the differences in the action potential duration or cardiac cycle length between the neonate and the adult.

In earlier literature, the age-related differences in the action potential were explained by the postnatal maturation of the $\mathrm{K}^{+}$ outward currents $(22,23)$. In neonatal mice, a dominant role of the $\mathrm{I}_{\mathrm{Kr}}$ rather than transient outward current was described (23). In rabbit ventricular myocytes, a postnatal decrease in the slope conductance and an increase in the extent of inward rectification have also been described (24). Nonetheless, postnatal changes in the $\mathrm{I}_{\mathrm{Kr}}$ of rabbits or humans have not been defined. We suspect a differential inhibition of the $I_{K r}$ by cisapride in neonatal hearts, but it is apparent that this needs to be confirmed by further research.

In the present study, the incidence of ventricular arrhythmias after cisapride in the neonate resembled that in the adult. The incidence was low (14\%) and did not increase with the concentration of cisapride. Other researchers have shown that the torsades de pointes appeared in two of six rabbits in vivo given cisapride and methoxamine (alpha-1 agonist) (7). In that model, concomitant infusion of the alpha- 1 adrenoceptor agonist methoxamine and class III antiarrhythmic agents (e.g. dofetilide) was consistently accompanied by the appearance of torsades de pointes (25). The relatively low incidence of torsades de pointes after cisapride and methoxamine was attributed to an alpha-1 adrenoceptor blocking effect of cisapride (7). In the present experimental model using Langendorff perfusion, the autonomic influence was minimal. It seems more reasonable that the cisapride-related arrhythmogenesis is closely associated with cisapride-induced QT prolongation.

Throughout the experiments here, atrial refractoriness was not modified. As shown in earlier studies, the $\mathrm{I}_{\mathrm{Kr}}$ plays a major role in the repolarization of cardiac ventricular tissue, whereas the $\mathrm{I}_{\text {to }}$ is more dominant in the atrial tissue (26). Hence, the selectivity of the $\mathrm{K}^{+}$channel blockade may account for the profile of electrophysiological modulation after cisapride.

\section{CONCLUSION}

In conclusion, cisapride at clinically relevant doses may modify the refractoriness of cardiac tissue, especially of the His-Purkinje system. The sensitivity to cisapride is definitively 
shown to be age related and to be higher in the neonate than in the adult. The high susceptibility of the His-Purkinje system to cisapride may cause infranodal AV block in the neonate. Therefore, the use of a narrower safety range of cisapride concentrations in the young is recommended.

\section{REFERENCES}

1. Wysowski KD, Bacsanyi J 1996 Cisapride and fatal arrhythmia. N Engl J Med 335:290-291

2. Ahmad SR, Wolfe SM 1995 Cisapride and torsades de pointes. Lancet 345:508

3. Vandenplas Y, Belli DC, Benatar A, Cadranel S, Cucchiara S, Dupont C 1999 The role of cisapride in the treatment of pediatric gastroesophageal reflux. J Pediatr Gastroenterol Nutr 28:518-528

4. Akbarali HI, Thatte H, He XD, Giles WR, Goyal RK 1999 Role of HERG-like K (+) currents in opossum esophageal circular smooth muscle. Am J Physiol 277:C1284 C1290

5. Chen HT, Goh MH, Pan S 1993 The effect and mechanism of the prokinetic action of cisapride on gastrointestinal smooth muscle. Gastroenterol Jpn 28:218-223

6. Puisieux FL, Adamantidis MM, Dumotier BM, Dupuis AB 1996 Cisapride-induced prolongation of cardiac action potential and early afterdepolarizations in rabbit Purkinje fibers. Br J Pharmacol 117:1377-1379

7. Carlsson L, Amos GJ, Andersson B, Drews L, Duker G, Wadstedt G 1997 Electrophysiological characterization of the prokinetic agents cisapride and mosapride in vivo and in vitro: implications for proarrhythmic potential? J Pharmacol Exp The 282:220-227

8. Wu MH, Su MJ, Lue HC 1994 Age-related quinidine effects on ionic currents of rabbit cardiac myocytes. J Mol Cell Cardiol 26:1167-1177

9. Kilbon MJ, Fedida D 1990 A study of the developmental changes in outward currents of rat ventricular myocytes. J Physiol 430:37-60

10. Hill SL, Evangelista JK, Pizzi AM, Mobassaleh M, Fulton R, Berul CI 1998 Proarrhythmia associated with cisapride in children. Pediatrics 101:1053-1156

11. Lewin MB, Bryant RM, Fenrich AL, Grifka RG 1996 Cisapride-induced long QT interval. J Pediatr 128:279-281
12. Wu MH, Su MJ, Lee SS, Young ML 1994 The electrophysiological effects of antiarrhythmic potential of a secoaporphine, $\mathrm{N}$-allylsecoboldine. Br J Pharmacol 113:221-227

13. Stevens J 1996 Applied Multivariate Statistics for the Social Sciences, 3rd Ed Lawrence Erlbaum Associates, New Jersey, pp 450-478

14. Rampe D, Roy ML, Dennis A, Brown AM 1997 A mechanism for the proarrhythmic effects of cisapride (Propulsid): high affinity blockade of the human cardiac potassium channel HERG. FEBS Lett 417:28-32

15. Wiseman LR, Faulds D 1994 Cisapride. An updated review of its pharmacology and therapeutic efficacy as a prokinetic agent in gastrointestinal motility disorders. Drugs 47:116-152

16. Preechagoon Y, Charles B, Piotrovskij V, Donovan T, Van Peer A 1999 Population pharmacokinetics of enterally administered cisapride in young infants with gastrooesophageal reflux. Br J Clin Pharmacol 48:688-693

17. Drolet B, Khalifa M, Daleau P, Hamelin BA, Turgeon J 1998 Block of the rapid component of the delayed rectifier potassium current by the prokinetic agent cisapride underlies drug-related lengthening of the QT interval. Circulation 97:204-210

18. Walker BD, Singleton CB, Bursill JA, Wyse KR, Valenzuela SM, Qiu MR, Breit SN, Campbell TJ 1999 Inhibition of the human ether-a-go-go-related gene (HERG) potassium channel by cisapride: affinity for open and inactivated states. $\mathrm{Br} \mathrm{J}$ Pharmacol 128:444-450

19. Carmeliet E 1992 Voltage and time-dependent block of the delayed $\mathrm{K}^{+}$current in cardiac myocytes by dofetilide. J Pharmacol Exp Ther 262:809-817

20. Scamps F, Carmeliet E 1989 Delayed $\mathrm{K}^{+}$current and external $\mathrm{K}^{+}$in single cardiac Purkinje cells. Am J Physiol 257:C1086-C1092

21. Nattel S 1999 The molecular and ionic specificity of antiarrhythmic drug actions J Cardiovasc Electrophysiol 10:272-282

22. Reder RF, Miura DS, Danilo P, Rosen MR 1981 The electrophysiological properties of normal neonatal and adult cardiac Purkinje fibers. Circ Res 48:658-668

23. Wang L, Swirp S, Duff H 2000 Age-dependent response of the electrocardiogram to $\mathrm{K}^{(+)}$channel blockers in mice. Am J Physiol 278:C73-C80

24. Wu MH, Su MJ, Lue HC 1993 Postnatal maturation of inwardly rectifying potassium current in isolated ventricular myocytes. J Formos Med Assoc 92:15-9

25. Carlsson L, Abrahamsson C, Andersson B, Duker G, Schiller-Linhardt G 1993 Proarrhythmic effects of the class III antiarrhythmic agent almokalant: importance of infusion rate, QT dispersion and early afterdepolarizations. Cardiovasc Res 27:21862193

26. Giles WR, Imaizumi Y 1988 Comparison of potassium currents in rabbit atrial and ventricular cells. J Physiol (Lond) 405:123-145 